\title{
Comparison of Strategies to Manage Stress Considering to Selected Socio-demographic Characteristics of Employees
}

\author{
Tatiana Lorincová1* \\ 1 Department of Managerial Psychology, Faculty of Management, Presov University in Presov, \\ Konštantinova 16, 080 01, Prešov, Slovakia \\ *Corresponding author, e-mail: tatiana.lorincova@unipo.sk
}

Received: 15 November 2017, Accepted: 28 March 2018, Published online: 06 August 2018

\begin{abstract}
The presented paper deals with the analysis of selected stress management strategies considering to gender and position in organization in which individual employees work. The aim of the paper is to compare the ways of managing and processing the stressful situations, as well as their variability with regard to the group of respondents, their inclusion in the organization (manager or executive employee) and the size of organization (small and medium organization). The research was conducted by using two methodologies, namely Brief COPE from Carver (1997) and SVF 78 by Janke and Erdmann (2003). The research sample consisted of 130 respondents aged 19 to 63 (mean age 40.38 with a standard deviation of 6.73 ), namely $53.8 \%$ of males and $47.2 \%$ of women. The research sample consisted of executive employees (49.2\%) and managers (50.8\%) working in a small and medium-sized organization. The research results were analyzed by t-test for two independent samples, namely the individual stress management strategies were compared. We found statistically significant differences in the level of control of the situation, self-blaming, POZ 1 and NEG among executive employees and managers. At the level of perseverance, self-blaming, religiosity and spirituality, and NEG we found statistically significant gender differences. Comparison of employees working in a small and medium-sized organization has demonstrated the existence of statistically significant differences in levels of underestimation, negation, ventilation and self-blaming. The most common strategy of stress management was the strategy of self-blaming, given the analyzed socio-demographic characteristics of the respondents.
\end{abstract}

Keywords

stress, managing stress, coping, gender, working position

\section{Introduction}

Stress is believed to be a state of the mind as well, as the body, created by certain biochemical reactions in the human body as well as psychological responses to situations, and is reflected by a sense of anxiety, tension and depression and is caused by such demands by the environmental forces or internal forces that cannot be met by the resources available to the person (Suresh, 2008). Krantz et al. (1985) suggested that workplace stress is a complicated psychological construct which must be first conceptualized by its parent construct known as stress. Stress has been defined as the change in one's physical or mental state in response to situations (stressors) that pose challenge or threat. Stress has also led to changes in work habits, changes in personality (or social behavior), and job burnout (Colligan and Higgins, 2006). Workplace stress is associated with coping strategies in the context of dealing with difficult situation related to stress.
Embedded in the ways of coping scale is a distinction between two general types of coping. The first, termed problem-focused coping, is aimed at problem solving or doing something to alter the source of the stress (Carver et al., 1989). The second, termed emotion-focused coping, is aimed at reducing or managing the emotional distress that is associated with (or cued by) the situation (Frankovský and Birknerová, 2015). Although most stressors elicit both types of coping, problem-focused coping tends to predominate when people feel that something constructive can be done, whereas emotion-focused coping tends to predominate when people feel that the stressor is something that must be endured (Folkman and Lazarus, 1980). In the context of theoretical backgrounds it is necessary to mention coping strategies or stress management strategies using in research.

Samson and Gross (2012) suggest that humour has long been seen as a particularly healthy and effective coping 
strategy. This is because humour is thought to be a powerful antidote to negative emotions (Vaillant, 2000). The active use of humour has a stress-moderating effect: creating a humorous narrative while viewing a stressful film resulted in a reduced physiological stress response, less emotional distress and lower negative affect than creating a serious narrative (e.g., Lefcourt and Martin, 1986; Newman and Stone, 1996). This effect was found in participants with both low and high trait humour, suggesting that humour production may be an effective coping strategy, even for individuals who do not typically use humour (Newman and Stone, 1996).

A good deal of research indicates that the personality dimension of optimis-pessimism plays an important role in a wide range of behavioral and psychological outcomes when people confront adversity. One of the possibilities is that optimists do better than pessimists because they cope more effectively (Carver et al., 1993).

Optimistic individuals are positive about events in daily life. In the research carried out regarding this perspective, positive correlations have been found between optimism and physical/mental well-being. Optimistic subjects tend to have more frequently protective attitudes, are more resilient to stress and are inclined to use more appropriate coping strategies (Conversano et al., 2010). Optimism is an "attributional style", characterized by the tendency to believe that negative events are inconstant (the negative event will not repeat itself), external (I am not responsible for the event) and specific (the event is "specific", self-limiting and will not influence any other activities of mine and my life). Optimists believe that positive events are more stable and frequent than negative ones. They think that they can avoid problems in daily life and prevent them from happening, and therefore they cope with stressful situations more successfully than pessimists (Aspinwall, Richter and Hoffman, 2001; Peterson and De Avila, 1995).

Spirituality is another coping method in wellness and in a variety of diseases. Such spirituality is defined as the capacity to rise above life experiences, to celebrate life, and to experience joy (Kuhn, 1988; Vastyan, 1986). Although closely related, spirituality and religiosity are considered distinct concepts. Spirituality applies to all mankind and involves the need for love, acceptance, forgiveness, and self-fulfillment, whereas religiosity applies to a specific religion or religious group (Chapman, 1986; Highfield and Cason, 1983). Each concept plays a role in determining spiritual well-being. Spiritual well-being has been described as a twofold state, including (1) a religious component (a positive specific relationship with God) and (2) a spiritual or existential component (a sense of life purpose and satisfaction) (Ellison, 1983). There is a positive relation between spiritual well-being and psychological well-being, an inverse relation between existentialism and depression, and a direct association of spirituality with hope or future-oriented goal setting (Landis, 1996). Spirituality can diminish depression, anxiety, and helplessness and can promote better mental health.

The interaction between the individual characteristics with the resources and the stress characteristics will influence how the individual responds on a cognitive, emotional, behavioral, and physiological level. When individuals do not have the capacity to adapt to the stressors, the effects can create chronic emotional, psychological, and physical complications-some lethal (Zimbardo et al., 2003).

Over the years, a great deal of research and theory has focused on the ways people deal with difficulties they encounter in their day to day lives. Scheier and Carver (1985) have suggested that dispositional optimism may have implications for the manner in which people deal with these stresses of life (cf. Lazarus et al., 1980; Reker and Wong, 1985). Definitions mentioned above form the basis for empirical part of our research.

\section{Methodology}

The main goal of the research is to compare strategies how to manage stress and their variability in the context of gender and work position.

Hypothesis 1: We assume statistically significant differences in the level of selected coping strategies in the context of gender.

Hypothesis 2: We assume statistically significant differences in the level of selected coping strategies between managing and executive employees.

Hypothesis 3: We assume statistically significant differences in the level of selected coping strategies between executive and managing employees in the context of gender.

\section{Research sample}

Research sample consisted of 130 respondents aged from 19 to 63 years (average age was 40.38 with standard deviation 6.73). The proportionality of gender was uneventhe sample contained $53.8 \%$ men and $47.2 \%$ women. The research sample consisted of $49.2 \%$ executive employees and 50.8\% managing employees working in small and medium organization. 


\section{Research methods}

We used two self-reported questionnaires for research purpose called Brief COPE developed by Carver (1997) and SVF 78 developed by Janke and Erdmann (2003).

\subsection{Brief COPE}

The Brief COPE (Carver, 1997) is a self-report questionnaire used to assess a number of different coping behavior and thoughts a person may have in response to a specific situation. It is made up of 14 subscales: self-distraction, active coping, denial, substance use, use of emotional support, use of instrumental support, behavioural disengagement, venting, positive reframing, planning, humour, acceptance, religion, and self- blame. After reading a situationally- specific scenario, 28 coping behaviours and thoughts (2 items for each subscale) are rated on frequency of use by the participant with a scale of 1 (-I haven't been doing this at alll) to (-I've been doing this a lotll). Internal reliabilities for the 14 subscales range from $\alpha=0.57$ - 0.90 (Carver, 1997).

\subsection{SVF 78}

We used the Czech version of the German Stress coping style questionnaire SVF 78 (Janke and Erdmannová, 2003, Janke and Erdmann, 2002). Stress coping style questionnaire contains 78 statements about dealing with stress and using coping strategies. The respondent evaluates each item using a 5-points Likert scale, ranging from "Not at all" to "Very likely". The 78 items are divided into 13 subscales, each represent a particular way of reacting to a stressful event: Underestimation, Guilt rejection, Tilt, Substitutional satisfaction, Control of situation, Control of reaction, Positive self-instruction, Need for social support, Active avoidance, Flight tendency, Rumination, Resignation, Self-blaming. Strategy POZ 1 is combination of average score of two subscales, specifically Underestimating and Guilt rejection. POZ 2 is a combination of Tilt and Substitutional satisfaction. POZ 3 is a combination of average score of Control of situation, Control of reaction and Positive self-instruction. And finally strategy NEG is a combination of average score of negative strategies, specifically Self-blaming, Resignation, Rumination and Flight tendency. Internal reliabilities for the 13 subscales range from $\alpha=0.77-0.94$.

\section{Research results}

The objective of the research is to analyze and compare selected stress management strategies among women and men in relation to their work position. In the research were compared coping strategies which were statistically significant and on the other hand have been other coping strategies excluded from the research. The results were processed in statistical program IBM SPSS 20.00 and assess by Two-way mixed Analysis of Variances (ANOVA). Table 1 illustrates descriptive data dependent and independent variables. Levene's test of Equality of Error Variances was higher than 0.05 in all cases. The value of F-ratio is highly significant.

Table 1 Descriptive statistics of dependent and independent variables

\begin{tabular}{|c|c|c|c|c|c|}
\hline Dependent & Independent & Independent & $\mathrm{N}$ & Mean & SD \\
\hline \multirow{4}{*}{ POZ 1} & \multirow{2}{*}{ Executive } & Women & 52 & 2.28 & 0.50 \\
\hline & & Men & 18 & 2.21 & 0.84 \\
\hline & \multirow{2}{*}{ Manager } & Women & 14 & 2.51 & 0.66 \\
\hline & & Men & 46 & 2.01 & 0.65 \\
\hline \multirow{4}{*}{ POZ 2} & \multirow{2}{*}{ Executive } & Women & 52 & 2.26 & 0.63 \\
\hline & & Men & 18 & 2.53 & 0.56 \\
\hline & \multirow{2}{*}{ Manager } & Women & 14 & 2.63 & 0.59 \\
\hline & & Men & 46 & 2.26 & 0.68 \\
\hline \multirow{4}{*}{ POZ 3} & \multirow{2}{*}{ Executive } & Women & 52 & 3.02 & 0.45 \\
\hline & & Men & 18 & 2.82 & 0.69 \\
\hline & \multirow{2}{*}{ Manager } & Women & 14 & 3.01 & 0.48 \\
\hline & & Men & 46 & 2.89 & 0.48 \\
\hline \multirow{4}{*}{ NEG } & \multirow{2}{*}{ Executive } & Women & 52 & 1.94 & 0.51 \\
\hline & & Men & 18 & 1.93 & 0.71 \\
\hline & \multirow{2}{*}{ Manager } & Women & 14 & 2.04 & 0.58 \\
\hline & & Men & 46 & 2.25 & 0.55 \\
\hline \multirow{4}{*}{$\begin{array}{l}\text { Active } \\
\text { coping }\end{array}$} & \multirow{2}{*}{ Executive } & Women & 52 & 5.02 & 0.91 \\
\hline & & Men & 18 & 4.90 & 1.01 \\
\hline & \multirow{2}{*}{ Manager } & Women & 14 & 5.00 & 0.78 \\
\hline & & Men & 46 & 4.83 & 1.14 \\
\hline \multirow{4}{*}{ Planning } & \multirow{2}{*}{ Executive } & Women & 52 & 4.80 & 0.91 \\
\hline & & Men & 18 & 4.69 & 0.69 \\
\hline & Mono & Women & 14 & 4.68 & 1.03 \\
\hline & ivrandager & Men & 46 & 4.67 & 0.96 \\
\hline \multirow{4}{*}{ Acceptance } & \multirow{2}{*}{ Executive } & Women & 52 & 4.28 & 1.11 \\
\hline & & Men & 18 & 4.69 & 0.91 \\
\hline & \multirow{2}{*}{ Manager } & Women & 14 & 4.61 & 1.11 \\
\hline & & Men & 46 & 4.14 & 1.04 \\
\hline \multirow{4}{*}{ Humour } & \multirow{2}{*}{ Executive } & Women & 52 & 2.78 & 1.31 \\
\hline & & Men & 18 & 3.64 & 1.85 \\
\hline & \multirow{2}{*}{ Manager } & Women & 14 & 3.18 & 1.58 \\
\hline & & Men & 46 & 2.51 & 1.42 \\
\hline \multirow{4}{*}{$\begin{array}{l}\text { Religion and } \\
\text { spirituality }\end{array}$} & \multirow{2}{*}{ Executive } & Women & 52 & 2.93 & 1.78 \\
\hline & & Men & 18 & 2.42 & 1.35 \\
\hline & \multirow{2}{*}{ Manager } & Women & 14 & 3.86 & 1.74 \\
\hline & & Men & 46 & 3.68 & 1.70 \\
\hline
\end{tabular}


Results analysis of research shows significant gender differences in the level of selected stress management strategies in relation to their work sector. Table 2 illustrates significant differences in all three cases.

Tests of between subject effects show significant differences in the level of religion and spirituality between men and women. Using Analysis of Variances we found

Table 2 Interaction effect of gender and work position-Multivariate tests

\begin{tabular}{lccc}
\hline & Tests & F ratio & Sig. \\
\hline \multirow{2}{*}{ Gender } & Pillai's Trace & 1.978 & $\mathbf{0 . 0 4 2}$ \\
& Wilks' Lambda & 1.978 & $\mathbf{0 . 0 4 2}$ \\
\hline \multirow{2}{*}{ Work position } & Pillai's Trace & 1.240 & 0.273 \\
& Wilks' Lambda & 1.240 & 0.273 \\
\hline \multirow{2}{*}{ Gender*Work } & Pillai's Trace & 2.027 & $\mathbf{0 . 0 3 6}$ \\
position & Wilks' Lambda & 2.027 & $\mathbf{0 . 0 3 6}$ \\
\hline
\end{tabular}

Table 3 Interaction Effect of Gender and Work position in the level of coping strategies - Tests of between Subject Effects

\begin{tabular}{|c|c|c|c|c|}
\hline $\begin{array}{l}\text { Dependent } \\
\text { variable }\end{array}$ & Independent variable & $\begin{array}{l}\text { Mean } \\
\text { square }\end{array}$ & F ratio & Sig. \\
\hline \multirow{9}{*}{ Gender } & POZ 1 & 0.005 & 0.012 & 0.912 \\
\hline & POZ 2 & 0.067 & 0.167 & 0.684 \\
\hline & POZ 3 & 0.098 & 0.400 & 0.528 \\
\hline & NEG & 1.071 & 3.361 & 0.069 \\
\hline & Active coping & 0.030 & 0.034 & 0.855 \\
\hline & Planning & 0.117 & 0.139 & 0.710 \\
\hline & Acceptance & 0.301 & 0.269 & 0.605 \\
\hline & Humour & 3.075 & 1.442 & 0.232 \\
\hline & Religion,spirituality & 28.62 & 9.976 & 0.002 \\
\hline \multirow{9}{*}{$\begin{array}{l}\text { Work } \\
\text { position }\end{array}$} & POZ 1 & 1.031 & 2.624 & 0.108 \\
\hline & POZ 2 & 2.386 & 5.890 & 0.017 \\
\hline & POZ 3 & 0.000 & 0.002 & 0.966 \\
\hline & NEG & 0.269 & 0.846 & 0.360 \\
\hline & Active coping & 0.072 & 0.079 & 0.779 \\
\hline & Planning & 0.058 & 0.069 & 0.793 \\
\hline & Acceptance & 4.626 & 4.128 & 0.044 \\
\hline & Humour & 14.07 & 6.599 & 0.011 \\
\hline & Religion, spirituality & 0.703 & 0.245 & 0.621 \\
\hline \multirow{9}{*}{$\begin{array}{l}\text { Gender } \\
* \text { Work } \\
\text { position }\end{array}$} & POZ 1 & 1.031 & 2.624 & 0.105 \\
\hline & POZ 2 & 2.386 & 5.890 & 0.017 \\
\hline & POZ 3 & 0.000 & 0.002 & 0.966 \\
\hline & NEG & 0.269 & 0.845 & 0.360 \\
\hline & Active coping & 0.072 & 0.079 & 0.779 \\
\hline & Planning & 0.058 & 0.069 & 0.793 \\
\hline & Acceptance & 4.626 & 4.128 & 0.044 \\
\hline & Humour & 14.07 & 6.599 & 0.011 \\
\hline & Religion, spirituality & 0.703 & 0.245 & 0.621 \\
\hline
\end{tabular}

statistically significant differences in the level of $\mathrm{POZ}$ $2(p=0.002)$, acceptance (0.004) a humour $(p=0.011)$ between managing and executive employees. We found statistically significant gender differences in the level of POZ 2, acceptance and humour between managing and executive employees.

Hypothesis 1 was confirmed in one case, because we found statistically significant gender differences in the level of religion and spirituality $(p=0.002)$. Women dispose with higher level of religion and spirituality and it means that they use this type of strategy when they are dealing with stress. Hypothesis 2 was confirmed in three cases, because we found statistically significant differences in the level of POZ 2, acceptance and humour between managing and executive employees. Hypothesis 3 was confirmed in three cases, because we found statistically significant differences in the level of POZ 2, acceptance and humour between women and men in relation to their work position (managing and executive employees).

Fig. 1 illustrates interaction between gender and work position of employees in the level of POZ2. Comparison estimated marginal means in the level of acceptance showed that men, who are managers $(M=2.26)$ expressed significantly lower level of strategy POZ 2 than women, who are managers $(M=2.63)$. Men, who are executive employees (2.53) showed significant higher level of strategy POZ2 than women, who are executive employees $(\mathrm{M}=2.26)$.

Fig. 2 illustrates interaction between gender and work position of employees in the level of acceptance. Comparison estimated marginal means in the level of

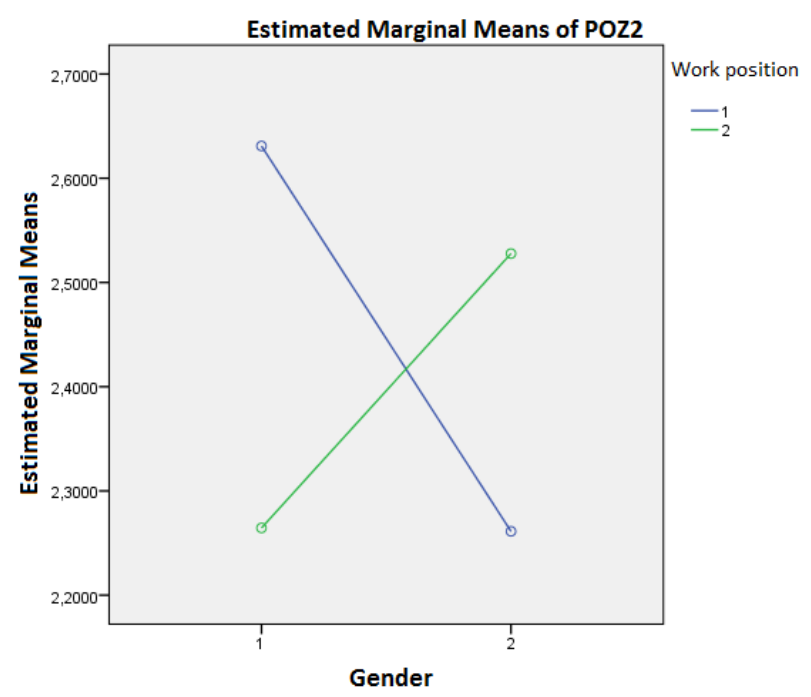

Fig. 1 Interaction between Gender and Work position of Employees in the level of POZ 2 


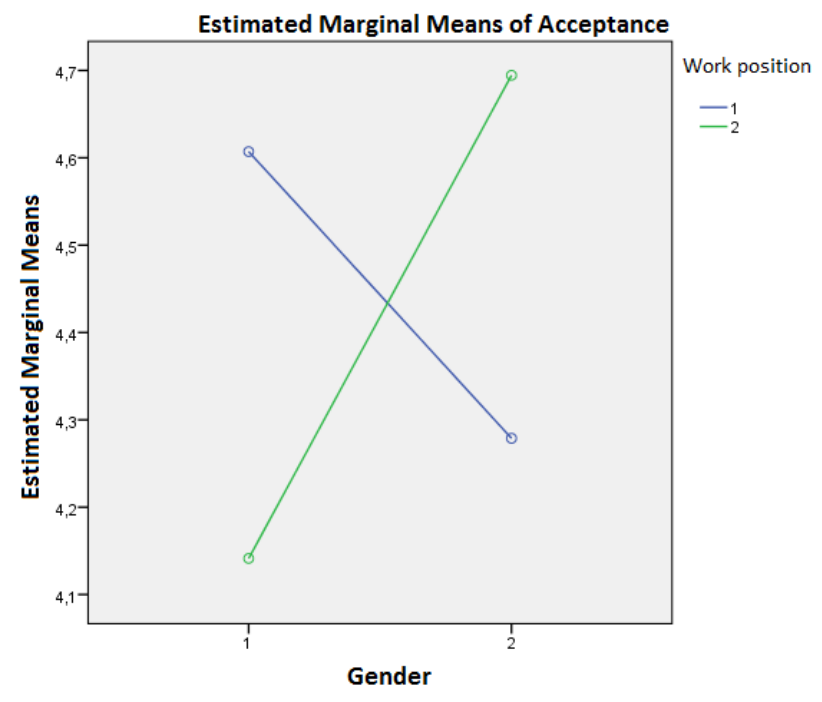

Fig. 2 Interaction between Gender and Work position of Employees in the level of Acceptance

Empathy showed men, who are managers $(\mathrm{M}=4.15)$ expressed significantly lower level of strategy acceptance than women, who are managers $(\mathrm{M}=4.61)$. Men, who are executive employees (4.69) showed significant higher level of strategy acceptance than women, who are executive employees $(\mathrm{M}=4.28)$.

Fig. 3 illustrates interaction between gender and work position of employees in the level of humour. Comparison estimated marginal means in the level of humour showed that men, who are managers $(\mathrm{M}=2.51)$ expressed significantly lower level of humour than women, who are managers $(M=3.18)$. Men, who are executive employees (3.64) showed significant higher level of humour than women, who are executive employees $(M=2.78)$.

\section{Discussion and conclusion}

In this chapter we will interpret the research findings according to comparison of selected socio-demographic characteristics in relation to ability how to manage and deal with stress.

We assumed statistically significant differences in the level of selected coping strategies in the context of gender. We found statistically significant gender differences in the level of religion and spirituality. Women dispose with higher level of religion and spirituality and it means that they use this type of strategy more often, when they are dealing with stress. Previous research showed that the coping mechanism which are religious/spiritual beliefs had helped individuals make sense of the caregiving experience. It should be noted that, in our conceptual model, we

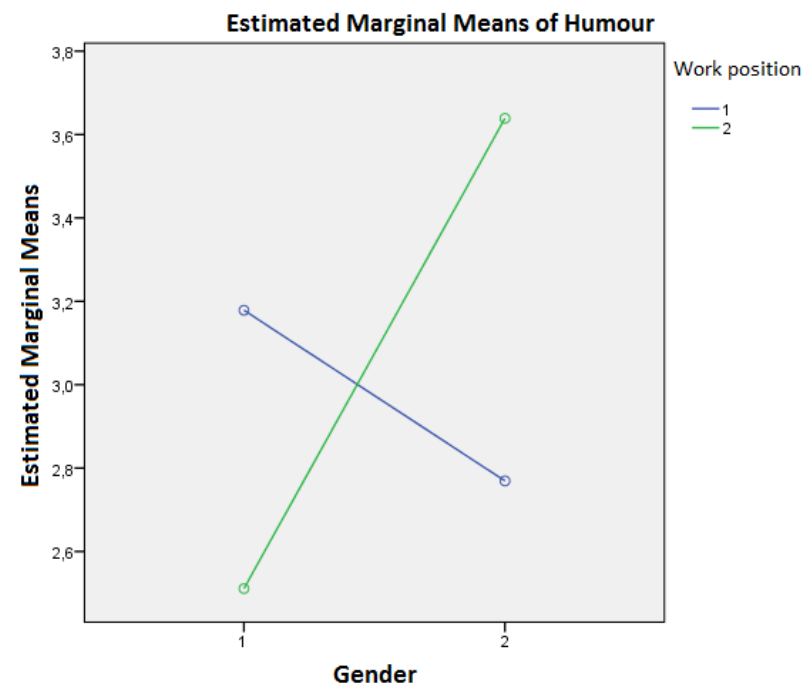

Fig. 3 Interaction between Gender and Work position of Employees in the level of Humour

assumed a direct association between stressors and religious/spiritual coping (Chang et al., 1998). Our research findings showed the importance of coping mechanism called religion and spirituality, which helped women how to deal with stressful situations in managerial work.

We assumed statistically significant differences in the level of selected coping strategies between managing and executive employees. We found statistically significant differences in the level of POZ 2 (positive coping strategies), acceptance and humour between managing and executive employees. Managing employees dispose with higher level of coping strategy POZ 2 and on the other hand executive employees dispose with higher level of two coping strategies: acceptance and humour. Humour has been described as producing a cognitive-affective shift or a restructuring of the situation so that it is less threatening, with a concomitant release of emotion associated with the perceived threat (Dixon 1980; Martin et al., 1993) and reduction in physiological arousal (Shurcliff, 1968). Abel (2002) assumed that humour may thus afford the opportunity for exploring cognitive alternatives in response to stressful situations and reducing the negative affective consequences of a real or perceived threat. The cognitive-affective shift is related to the transactional model of stress proposed by Lazarus et al. (1980).

We assumed statistically significant differences in the level of selected coping strategies between executive and managing employees in the context of gender. We found statistically significant differences in the level of POZ 2, acceptance and humour. Men, who are managers 
expressed significantly lower level of humour than women, who are managers. Men, who are executive employees showed significant higher level of humour than women, who are executive employees. In the level of coping strategy acceptance expressed men, who are managers significantly lower level of acceptance than women, who are managers. Men, who are executive employees showed significant higher level of strategy acceptance than women, who are executive employees. Men, who are managers expressed significantly lower level of humour than women, who are managers. Men, who are executive employees showed significant higher level of humour than women, who are executive employees. Newman and Stone (1996) found that men with a good sense of humour appraised a serious video of an industrial accident as less stressful than those with a poor sense of humour. In addition, high trait humour men viewed the serious film as more humorous and they were more comfortable with composing a humorous narrative to the serious film than men with low trait humour. In a review of studies examining humour

\section{References}

Abel, M. H. (2002) "Humor, stress and coping strategies", Humor: International Journal of Humor Research, 15(4), pp. 365-381. https://doi.org/10.1515/humr.15.4.365

Aspinwall, L. G., Richter, L., Hoffman, R. R. (2001) "Understanding how optimism works: An examination of optimists adaptive moderation of belief and behaviour", In: Chang, C. E. (eds.) Optimism and pessimism, American Psychological Association, Washington, USA, pp. 217-238.

Carver, C. S. (1997) "You want to measure coping but your protocol's too long: Consider the brief cope", International Journal of Behavioral Medicine, 4(1), pp. 92-100. https://doi.org/10.1207/s15327558ijbm0401_6

Carver, C. S., Scheirer, M. F., Weintraub, J. K. (1989) "Assessing coping strategies: A theoretically based approach", Journal of Personality and Social Psychology, 56(2), pp. 267-283. https://doi.org/10.1037/0022-3514.56.2.267

Carver, C. S., Pozo, C., Harris, S. D., Noriega, V., Scheier, M. F., Robinson, D. S., Ketcham, A. S., Moffat Jr., F. L., Clark, K. C. (1993) "How coping mediates the effect of optimism on distress. A study of early stage breast cancer", Journal of Personality and Social Psychology, 65(2), pp. 375-390. https://doi.org/10.1037/0022-3514.65.2.375

Chang, B. H., Noonan, A. E., Tennstedt, S. L. (1998) "The Role of Religion/Spirituality in Coping with Caregiving for Disabled Elders", The Gerontologist, 38(4), pp. 463-470. https://doi.org/10.1093/geront/38.4.463

Chapman, L. S. (1986) "Spiritual Health: A Component Missing from Health Promotion", American Journal of Health Promotion, 1(1), pp. 38-41.

https://doi.org/10.4278/0890-1171-1.1.38 and appraisal, Martin (1996:p.266) suggested that a good sense of humour is related to more effective coping strategies of individuals via "their use of more realistic cognitive appraisals. Research findings are useful for creating a stress management program using strategies as a humour and spirituality in the context of soft skills training. Specifically, great value is in creation a new training for employees under stress using techniques as relaxation of own mind, self-observation with help of professional and using guided imaginary. In the context of humour strategy is a great way to reduce stress yoga of laughter. These findings can contribute to create educational program, which will help individuals how to deal with stressful situations in the context of stress management.

\section{Acknowledgement}

The research project presented in this article is supported by grant project 0033PU-4/2017 - KEGA (Implementation of interpersonal skills in the context of the Psychology of business - innovation of contents and teaching).

Colligan, T. W., Higgins, E. M. (2006) "Workplace Stress", Journal of Workplace Behavioral Health, 21(2), pp. 89-97. https://doi.org/10.1300/J490v21n02_07

Conversano, C., Rotondo, A., Lensi, E., Della Vista, O., Arpone, F., Reda, M. A. (2010) "Optimism and its impact on mental and physical well-being", Clinical Practice \& Epidemiology in Mental Health, 6, pp. 25-29. https://doi.org/10.2174/1745017901006010025

Dixon, N. F. (1980) "Humor. A cognitive alternative to stress", In: Spielberger, C. D., I. G. Sarason (eds.) Anxiety and stress, Hemisphere, Washington DC, USA, pp. 281-289.

Ellison, C. W. (1983) "Spiritual Well-Being: Conceptualization and Measurement", Journal of Psychology and Theology, 11(4), pp. 330-340. https://doi.org/10.1177/009164718301100406

Folkman, S., Lazarus, R. S. (1980). "An Analysis of Coping in a MiddleAged Community Sample", Journal of Health and Social Behavior, 21(3), pp. 219-239. https://doi.org/10.2307/2136617

Frankovský, M., Birknerová, Z. (2015) "Ways of coping with demanding managerial work situations and traits of interpersonal behavior", Journal of Management and Business, 7(2), pp. 25-34.

Highfield, M. F., Cason, C. (1983) "Spiritual needs of patients: Are they recognized?" Cancer Nursing, 6(3), pp. 187-192.

Janke, W., Erdmannová, G. (2003) "Strategie zvládaní stresu", SVF 78. (Coping strategies. SVF 78). (Transl. J Švancara). Testcentrum, Praha. (in Czech)

Janke, W., Ersmann, G. (2002) "Eine Kurzformdes Stressverarbeitungs fragebogens SVF 120", (Short form of Stress and Coping Style Questionnaire SVF 120) Manual. Hofgrefe, Götiingen. (in German) 
Krantz, D., Grunberg, N., Baum, A. (1985) "Health Psychology", Annual Review of Psychology, 36, pp. 349-383. https://doi.org/10.1146/annurev.ps.36.020185.002025

Kuhn, C. C. (1988) "A spiritual inventory of the medically ill patient", Psychiatric Medicine, 6(2), pp. 87-100.

Landis, B. J. (1996) "Uncertainty, Spiritual Well-Being and Psychosocial Adjustment to Chronic Illness", Issues in Mental Health Nursering, 17(1), pp. 217-231. https://doi.org//10.1016/S0883-9417(99)80064-8

Lazarus, R. S., Kanner, A. D., Folkman, S. (1980) "Emotions: A cognitive-phenomenological analysis", In: Plutchik, R., Kellerman, H. (eds.) Emotion: Theory, research, and experience, Academic Press, NewYork, USA, pp. 189-217.

Lefcourt, H. M., Martin, R. A. (1986) "Humor and Life Stress: Antidote to adversity", Springer-Verlag, New York, NY, USA. https://doi.org/10.1007/978-1-4612-4900-9

Martin, R. A. (1996) "The Situational Humor Response Questionnaire (SHRQ) and Coping Humor Scale (CHS): A decade of research findings", Humor: International Journal of Humor Research, 9(3-4), pp. $251-272$.

https://doi.org/10.1515/humr.1996.9.3-4.251

Martin, R. A., Kuiper, N. A., Olinger, L. J., Dance, K. A. (1993) "Humor, coping with stress, self-concept, and psychological well-being", Humor: International Journal of Humor Research, 6(1), pp. 89-104. https://doi.org/10.1515/humr.1993.6.1.89

Newman, M, G., Stone, A. A. (1996) "Does humor moderate the effects of experimentally-induced stress?". Annals of Behavioral Medicine, 18(2), pp. 101-109. https://doi.org/10.1007/BF02909582

Peterson, C., De Avila, M. E. (1995) "Optimistic explanatory style and the perception of health problems", Journal of Clinical Psychology, 51(1), pp. 128-132.

https://doi.org/10.1002/1097-4679(199501)51:1<128::AIDJCLP2270510120>3.0.CO;2-1
Reker, G. T., Wong, P. T. P. (1985) "Personal optimism, physical and mental health: The Triumph of succesful aging", In: Birren, J. E., Livingston, J. (eds.), Cognition, stress and aging, Prentice-Hall, EnGlewood Cliffs, NJ, USA, pp. 134-173.

Samson, A. C., Gross, J. J. (2012) "Humour as emotion regulation: The differential consequences of negative versus positive humour", Cognition and Emotion, 26(2), pp. 375-384. https://doi.org/10.1080/02699931.2011.585069

Shurcliff, A. (1968) "Judged humor, arousal, and the relief theory", Journal of Personality and Social Psychology, 8(4), pp. 360-363. https://doi.org/10.1037/h0025493

Scheier, M. F., Carver, C. S. (1985) "Optimism, coping and health: Assesment and implications of generalized outcome expectancies", Health Psychology, 4(3), pp. 219-247. https://doi.org/10.1037/0278-6133.4.3.219

Suresh, S. (2008) "Stress and Coping Strategies", Management and Labour Studies, 33(4), pp. 482-487. https://doi.org/10.1177/0258042X0803300403

Vaillant, G. E. (2000) "Adaptive mental mechanisms: Their role in a positive psychology", American Psychologist, 55(1), pp. 89-98. https://doi.org/10.1037//0003-066X.55.1.89

Vastyan, E. A. (1986) "Spiritual aspect of the care of cancer patients", CA: A Cancer Journal for Clinicians, 36(2), pp. 110-114. https://doi.org/10.3322/canjclin.36.2.110

Zimbardo, P., Weber, A., Johnson, R. (2003) "Psychology: Core concepts", 4th ed., Allyn \& Bacon, Boston, USA. 